\title{
Expanded Short Course Program Announced
}

\author{
New Topics, More Frequent Course Schedules, Special Course Packages
}

Beginning in 1986, the Materials Research Society will implement a major expansion of its highly successful Short Course Program. The expansion is intended to make course offerings more representative of the wide variety of materials topics addressed at MRS meetings. It will also provide participants greater opportunities to learn about the latest developments in important and emerging technologies in a tutorial setting through more frequent and flexible scheduling.

As a first step toward these goals, MRS has appointed Vivienne Harwood Mattox as short course manager. Her enthusiasm and experience with continuing education in the field of science and engineering will guide the development of the program. (See "Vivienne Harwood Mattox Appointed MRS Short Course Manager.")

MRS short courses are intense, one or multiple day instructional sessions dealing with the latest materials processing and characterization technologies. They benefit MRS members as well as the scientific and engineering community in general through coverage of basic, applied, advanced and specialty topics. The MRS Short Course Program has grown from one offering on Liquid Phase Epitaxy taught by L. R. Dawson in 1982 to 14 courses at the 1985 Fall Meeting in Boston.

\section{Core and Specialty Courses Planned}

The goal of the Short Course Program is to present high-quality, professional and comprehensive short courses which serve the needs of the materials science and engineering communities. As a result of expansion, both core and specialty courses are anticipated which will further this objective. Core-type courses are designed to provide thorough coverage of fundamental subject areas; specialty-type courses are graduate level courses on subjects of interest to specific groups. With the assistance of a Technical Development Subcommittee of the MRS Education Committee, new courses will be developed on topics which relate to the multi-dimensional interests of the Society.

Course content and course materials will receive peer review to ensure top-quality scientific content and will be taught by highly qualified instructors who have upto-date knowledge of the field. The courses will encompasscurrent theories, technology and equipment.

\section{Flexible Schedules, Adaptable Venues}

Future courses programs will be offered in several different forums. In general, programs offered at MRS Spring and Fall Meetings will span a five-day period to enable course attendees to register for more than one course as well as to attend the technical symposia. It is hoped that scheduling will enable most course topics to complement the symposia so that meeting attendees can also participate in the course program.

Reduced fees will be offered for course attendees who register for certain groups of courses in a topical series during a single time period. Priority registration will be given to persons who wish to register for these course packages.

Courses will also be offered on-site or locally in response to specific requests from organizations. On-site courses will provide all the advantages of a regular MRS course, plus the convenience and economy of enabling participants to remain at home. Some on-site courses will be developed specifically for technical personnel who are not free to attend courses away form their jobs.

To some degree, on-site courses can be customized to deal with specific problems of course attendees. The on-site program is intended to be responsive to the needs of MRS corporate affiliates and other industrial and federally funded organizations.

Long-range plans also provide for standalone groups of courses to be offered in convenient geographical locations, independent of MRS annual meetings.

\section{Member Participation Sought}

MRS members and othe individuals active in the materials science and engineering communities can assist in the growth of the MRS Short Course Program in a number of ways. Individuals are invited to recommend new course topics and instructors, and assist in peer review of courses and course materials. Individuals may also assist by making the MRS program known within their organization and to their local professional community.

If you are interested in providing names of potential new course topics and/or instructors for the program or would like to assist in promoting the program, contact Vivienne Harwood Mattox, MRS Short Course Manager, 440 Live Oak Loop, Albuquerque, NM 87122; telephone (505) 294-9532.

\section{NEW FROM MRE ON-SITE SHORT COURSES conducted at you own facilities or a nearby site}

The best way to keep your staff on top of their fields is through an on-going program of continuing education. One of the most efficient, cost-effective methods is to bring experts to your geographical location so that they can teach the latest techniques, discuss the newest research, and talk to your staff about the actual problems that they face daily.

The economic savings of On-Site progams are considerable, both in terms of time and budget. There are no travel fees or hotel costs for your staff, and attendees lose minimal time from their work.

MRS On-Site courses will be adapted to the specific needs of the sponsoring organization and the management will have an opportunity to interact with the instructor to discuss the course emphasis. Written requests from organizations will be handled on a first-come first-served basis. For further details of courses which are available, prices and other information, write or call:

Vivienne Harwood Mattox, Short Course Manager, Materials Research Society,440 Live Oak Loop, Albuquerque, NM 87122 ; telephone (505) 294-9532 